\title{
The Case of George Fitzsimmons \& the Practice of Forensic Psychology
}

\author{
Thomas W Miller* \\ Department of Gerontology \& Psychiatry, University of Kentucky, USA
}

Submission: May 07, 2017; Published: May 24, 2017

*Corresponding author: Thomas W Miller, Department of Gerontology \& Psychiatry, Professor Emeritus \& Senior Research Scientist, University of Kentucky, College of Medicine \& Public Health, USA, Email: tom.miller@uconn.edu

Abstract

Examined are the contributions that a forensic psychologist brings to the multidisciplinary forensic team. Addressed are a brief historical review of the emerging specialty of forensic clinical psychology with specific attention to the value of psychological contributions in the diagnosis and treatment of individuals who are provided interdisciplinary services within a designated forensic unit. The case of George Fitzsimmons who was indicted and tried for the murder of his parents and then his relatives to whom he was released is discussed from the perspective of the psychologist who worked this case. Protocols are discussed as being beneficial for the psychological evaluation of forensic cases referred and mandated to the forensic unit. Issues and important for further discussion is explored.

\section{Introduction}

Clinical psychology provides a critical role in the functioning of a forensic unit in a psychiatric hospital setting. Benjamin \& Baker [1] have summarized the specialties in psychology and among them in the 21st century is forensic psychology. According to the American Board of Forensic Psychology [2], forensic psychology is the application of the science and profession of psychology to questions and issues relating to law and the legal system Tartakovsky [3]. The word "forensic" comes from the Latin word "forensis," meaning "of the forum," where lawyers of the day discussed the issues of justice in ancient Rome. Today the concept of forensic has adopted an evidence based reference in the application of scientific principles and practices for the adversarial process in our justice system.

Forensic psychology is a specialized branch of public service psychology that deals with issues that connect psychology and the law. Interest in forensic psychology has grown significantly in recent years. Increasing numbers of graduate programs have developed dual degrees in psychology and law, with others providing specialization in forensic clinical psychology. This specialty forensic psychology dates back to the earliest days in psychological science when one considers the role of psychology in the study of criminal behavior. Stern [4] continued to study issues surrounding testimony and later established the first academic journal devoted to applied psychology. Forensic and public service psychologists are proficient in dissecting details and identifying and interpreting the psychological clues. But their background in human behavior often extends their work beyond the yellow police tape. In fact, they offer their expertise on many legal matters, including the mental state of criminal defendants. They may be called in to examine and determine whether a defendant should be declared incompetent to stand trial or receive a reduced sentence due to temporary insanity.

Forensic psychologists serve a number of important roles as they advise on jury selection, child custody and family law, violence risk prediction, mediation and dispute resolution, discrimination, civil damages, social science research, and civil commitment, where individuals with symptoms of severe mental illness are ordered by a court into treatment Bartol [5]. Some forensic psychologists work in the area of threat assessment, an emerging science predicting who may be at risk of committing a violent act. And others help select police officers and train first responders. Ultimately, forging the connection between psychology and the justice system is what they do best.

Clinical forensic psychologists contribute their specialty skills in prisons, rehabilitation centers, police departments, courthouses, law firms, schools, government agencies or private practices. They are needed to determine whether a suspected criminal has a mental illness, for example, and are called upon to treat incarcerated individuals with substance abuse and addiction issues. Their work also spans important legal activities 
that involve minors. They help children in suspected abuse cases to process and communicate their experiences truthfully and accurately, and may prepare them to testify in court or child custody disputes.

It is the forensic trained clinical psychologist who studies criminal behavior to determine common traits among types of perpetrators. This includes interviewing criminals, along with their loved ones and even victims. They focus on the study crime scenes and evaluate evidence left behind to develop a profile of a particular criminal and narrow a list of suspects. Forensic psychologists also take the stand in court to explain possible motives behind a crime or whether they feel a defendant is guilty based on what they know about his or her behavioral history. As a result, they may influence a criminal's sentencing. Research is a key component of a career in forensic psychology and it comes in several forms. The dominant model continues to be one in which an individual earns a doctoral degree in clinical psychology, and subsequently pursues a postdoctoral specialization in forensics. However, more graduate schools are adopting forensic tracks. Forensic psychology is a recognized specialty in professional psychology.

The American Psychological Association [6] embodies the specialty of forensics psychology through Divisions 18 Public Service and Division 41 Psychology \& the Law. Both these Divisions are inter-disciplinary organization devoted to scholarship, practice and public service in psychology and law American Psychological Association [6]. This professional organization notes that forensic psychology is a specialty in professional psychology characterized by activities primarily intended to provide professional psychological expertise within the judicial and legal systems.

\section{Psychology's Presence in the Forensic Unit Setting}

The model forensic unit in which this author served as a senior clinical psychologist providing a spectrum of psychological services ranging from clinical diagnostic interview, clinical assessment, and treatment based on best practices for the acute The Case of George Fitzsimmons

Table 1: "The Buffalo Ripper" asa "Karate Chop Killer". mentally ill patients Dietz [7], Drukteinis [8], Ferreira [9] who had been admitted to a forensic unit through court order because of criminal behavior. These are regionally based that serve the needs of various county jails in the region. In addition such a unit provides services for patients classified as chronically mentally ill individuals who are remanded to the facility by State Courts due to competency related issues. Finally, patients who are classified as harm to self or others or are considered dangerous legal standards are remanded to such facilities.

As with any medical and health care facility, there is a mission and vision statement that serves as a guide to the services and direction of the unit. Such a facility provides integrated and multidisciplinary evaluation, treatment, and rehabilitation services for those individuals who have committed some form of criminal behavior with serious mental illness. The goal is working toward recovery. The primary mission of a forensic unit is to provide evidence based inpatient psychiatric assessment, treatment and other relevant services for mentally ill individuals who are currently involved or were involved with the Criminal Justice System. Contemporary clinical psychologists with the specialty of forensic science are a professional that studies the thinking and behavior of criminals Seager [10], Schlesinger [11], Scholte [12], Stote \& Standing [13], Walters 2000). Such a career has received considerable note in recent years because of a number of popular television programs that depict forensic psychologists, such as Criminal Minds, the Crime Scene Investigation series and just this year with a focus on jury selection and behavior with the introduction of Bull. Considerable research attention has focused on serial killers and understanding the thinking and behavioral processes of this category of criminal activity Walters [14], Seager [10].

A case study may best exemplify the role and responsibilities of the clinical psychologist trained with a specialization in forensic science. This case study reflects the work of this author who provided through court order and evaluation of a patient who was determined to be criminally insane at the time of his initial serial murders.

\begin{tabular}{|r|}
\hline Birth name: George Kearon Joseph Fitzsimmons \\
\hline Date of birth: 1937 \\
\hline SEX: M; RACE: W; TYPE: N; MOTIVE: PC-nonspecific \\
\hline MO: Killed parents William Fitzsimmons, 64, and his wife, Peral, 60 (his parents) \\
\hline DISPOSITION: Ruled innocent by reason of insanity, \\
\hline 1969; Incarcerated on locked Forensic Unit \\
\hline Released from Forensic Unit (1973) \\
\hline Within one week after release, murders his aunt and uncle \\
\hline De Alton Nichols, 80, and his wife Euphrasia, 80 (his uncle and aunt) \\
\hline 1976 On Retrial, Court commits him to two concurrent life terms
\end{tabular}


The author of this chapter served as the forensic clinical psychologist who provided the psychological assessment, evaluation and testimony fora patient by the name of George Fitzsimons Newton [15]. In the forensic case the a defendant also known as "the Buffalo Ripper" and the "Karate Chop Killer" was judged to be "innocent by reason of insanity" at the time of the murders of his parents and placed in the custody of the state forensic psychiatric facility in New York Palermo \& Knudten [16]. He was committed by the court for rehabilitation for the murder of his parent by karate chopping them both to death in 1969. At that time he committed parricide murder, the killing of both his parents by karate chopping them to death. A summary of his historical background and criminal information file appear in (Table 1).

\section{Criminal Record}
a. Classification: Homicide - Murderer
b. Characteristics: Parricide
c. Date of murders: January 12, 1969 / November 18, 1973

d. Method of murder: "karate chopping"/Stabbing with a hunting knife.

\section{Court Rulings}

i. Ruled criminally insane, 1969. Pennsylvania

ii. Court assigned to State Forensic Psychiatric facility in Western New York

iii. Reevaluated for release after two years of good behavior on locked forensic unit

iv. Released for good behavior to family members, an aunt and uncle 1973.

v. Sentenced to two concurrent life terms, for multiple murders 1976

\section{The Initial Interview and Psychological Evaluation}

The primary tool of the forensic clinical psychologist includes a detailed review of previous and present medical records, history of criminal records, history court ordered evaluations and testimony. The critical components include but are not limited to his childhood; adolescence and adulthood thought processes and behavior In addition particular attention is given to any history of cruelty to animals and cruelty to children and peers. Special attention is paid to aggressive thoughts and lasting and recurring fantasies. The use and abuse of alcohol and substances of abuse, along with previous arrest record, authority issues and problems at home, in school and during employment are examined.

As an excellent protocol and guide for the forensic clinical psychologist is the Serial Murder Personality Protocol Keaton [17]. This is a structured Interview Checklist of Symptoms and Behavioral Experiences that must be addressed in a thorough evaluation before psychological testing is conducted. This structured clinical interview includes:
a. Symptom/Behavior Childhood Adolescence Adulthood
b. Accident prone
c. Aggressive fantasies
d. Alcohol abuse
e. Arrests
f. Authority problems
g. Chronic lying
h. Compulsive masturbation
i. Convulsions
j. Cruelty to animals
k. Cruelty to children
l. Dissociation

In addition, the Keaton Conceptualization of Personality Disorders Keaton [17] is a very meaningful measure in the forensic psychologist's tool box. This measure includes an assessment of multiple symptom and behaviors associated with criminal activities found during various phases of life usually classified by childhood, adolescence, and the adult life span. Special attention is paid to activities that include drug use and abuse, incidence of reported eating problems, enuresis, feared by others, feelings of helplessness, isolation, and for some feelings of omnipotence [18-21]. Also examined is the presence of delusions and/or hallucinations, any trauma to the brain or history of head presence and pattern of headaches, symptoms related to head injury, homicidal thoughts and Impulsivity.

\section{Components of the Psychological Evaluation}

A model forensic psychological assessment and evaluation should include the following components.

a. Source \& Reason for Referral.

b. The District Court ordered a psychological evaluation to assess the mental status of the patient with special attention to his cognitive functioning, does her understand right from wrong, and ability to understand the charges against him.

\section{Background Information}

The best remembered and most dramatic case of child-parent murder was the criminal activities of George Fitzsimmons who murdered his parents on January 12, 1969, by using "karate". George claimed that his father tried to hit him because he refused to go to church with his parents. George Fitzsimmons was 31 years old at the time [22]. William Fitzsimmons, 64, and his wife, Peral, 60, by their son George. In an effort to defend himself, he hit his father on the head several times and then beat his mother until she too was dead [23]. Thereafter, he drove to Rhode Island 
in his father's car where he was eventually Apprehended and tried for their murders double slaying, Fitzsimmons was sent to the Buffalo Psychiatric Center where he was eventually released in 1973 when court testimony revealed that the social worker had located a suitable placement with his only living relatives in Pennsylvania, an elderly aunt and uncle [24-26]. At first they were reluctant but eventually complied with the encouragement of the rehabilitation history of the patient.

\section{Court Ordered Psychological Evaluation}

A court ordered evaluation of the patient was issued and would include a psychiatric and clinical forensic evaluation

Table 2: Serial Murder Personality Protocol (SMPP). by the senior clinical psychologist before the court would entertain a recommendation $[27,28]$. Because of his inheritance, George Fitzsimons had the money to hire a well-established attorney and he sought the services of F. Lee Bailey Attorney at LawIn anticipation of his gaining release from the hospital. In court proceedings, the attorney challenges to the use and interpretation of psychological tests such as Rorschach and the MMPI findings was evident and influenced the court. As a result, the court focused on the general observations of the psychiatrist and the enthusiasm of the social work placement available in making its decision (Table 2).

\begin{tabular}{|c|}
\hline Method: Individual Psychological Assessment \\
\hline Interview: Structured Clinical Interview for Axis II DSM-IV Disorders \\
\hline SMPP Interview Checklist \\
\hline Psychological Measures as appropriate \\
\hline Appropriate Wechsler Scales \\
\hline Wechsler Adult Scales \\
\hline Mini Mental Status Exam \\
\hline Bender Gestalt \\
\hline Minnesota Multiphasic Personality Inventory \\
\hline Rorschach Inkblots \\
\hline MCMI-II \\
\hline MMPI-2 \\
\hline Rorschach or TAT \\
\hline Neurological Tests Halstead-Reitan Neuropsychological Battery with selected Scales \\
\hline
\end{tabular}

\section{Laboratory Panels}

a) Electroencephalograph (EEG)

b) Computerized tomography imaging (CT scan)

c) Chromosome analysis

\section{Public Records}

a. Record Review Education with school reports related to behavior

b. Military/Employment

c. Legal records including history of arrest and conviction

d. Medical records including general history of wellness

e. Psychological Evaluations previously completed

\section{Interview with Collateral Sources}

The following individuals familiar with the patient should be interviewed. A summary of family, friends and relatives would be noted. This could also include any number of coworkers/neighbors/nurses/doctors/etc.). The Psychological Evaluation and Assessment was conducted by this author [29]. At the completion of the psychological evaluation, the senior psychologist met with the social worker and the psychiatrist and argued the case that based on his psychological testing, the results argued against releasing him from the hospital on the basis of high acting out behavior [30-33]. There was enough evidence from the psychological testing of the presence of a sociopathic personality disorder along with strong indications of acting out potential more likely against others than against self. Among the team members, the psychiatrist failed to see any evidence that argued against his release and the social work was eager to see him assume his placement with his aunt and uncle.

This was a time when there was pressure to reduce the psychiatric facilities census and place psychiatric patients in the community. Outpatient care was encouraged for such patients. Having obtained a placement option, the social worker argued strongly in favor of his release and with the psychiatrist's support and against the advice noted in the psychological report, George Fitsimmons was judged to be appropriate for placement with his aunt and uncle by the court. In less than two weeks, George Fitzsimons returned to the Forensic psychiatric center and turned himself in. In the car was the knife that he used to kill both his aunt and his uncle in rural Pennsylvania. It was little satisfaction to this writer that both the psychiatrist and the social worker apologized to me for their decision to base their 
recommendations on impressions that they had when I had the data to argue against the decision to release this serial criminal.

The testimony of the psychiatrist of record testified that he was ready for release on the grounds that "he is without danger to himself and others." Having inherited $\$ 123,000$ from his parents, Fitzsimmons went to Potter County in Pennsylvania to stay with his aunt and uncle, both in their eighties. Within a week after he was placed with them, he stabbed both Euphrasia Nichols, his aunt, and De Alton Nichols, his uncle, to death with a hunting knife. He drove their car back to the institution that had recommended his placement outside the forensic facility and discharged him with the decision of the court. The roles of the forensic psychologist as expert witness are as experimental psychologist, actuary, and medical witness. In the first of these roles, the experimentalist can offer evidence in three ways. He/ she can comment on experimental data from the general body of psychological knowledge, provide evidence from his/her own clinical, psychological tests, laboratory studies, or report on field studies he/she has conducted in relation to the case at issue.

In the role of actuary, the forensic psychologist can provide the court with data which gives the probability of a particular event or circumstance happening or the mean value of something. The psychologist as actuary is basing calculations on all the relevant observations made by psychologists through the years, but in particular cases, he/she may go into the field for observations. Probability statements, however, are used less in court than in helping the police to decide whether to pursue a particular line of investigation. In the role of medical witness, the psychologist may provide supplementary or complementary evidence bearing upon other medical evidence (for example, to the neurologist in compensation cases, or to the psychiatrist in criminal cases), or provide independent evidence. In civil cases, the forensic psychologist is most often concerned with compensation cases.

The psychologist also may function in the court of chancery when an appellant is trying to gain freedom from the court of protection. The psychologist may be asked to testify about the appellant's ability to handle his/her own affairs. Other legal contexts where the psychologist may contribute medical evidence are mental health tribunals, divorce proceedings, and criminal trials, where the psychologist may be concerned with the application of $\mathrm{M}^{\prime}$ Naghten rule and the legal concept of diminished responsibility.

\section{References}

1. Benjamin LT, Baker DB (2004) The psychological profession in the $21^{\text {st }}$ century: New practice specialties. From Seance to Science: A History of the Profession of Psychology in America. Wadsworth/Thomson Learning, California, USA, pp. 200-204.

2. American Board of Forensic Psychology (2011) Definition of Forensic Psychology. Chapel Hill, North Carolina, USA.

3. Tartakovsky M (2011) How Forensic Psychology Began and Flourished. Psych Central, USA.
4. Stern SB, CA Smith (1995) Family processes and delinquency in an ecological context. Social Service Review 69(4): 703-731.

5. Bartol C, Bartol A (2008) Criminal Behavior-A Psychosocial Approach ( $8^{\text {th }}$ edn), Upper Saddle River, Pearson Education, Inc, New Jersey, USA

6. American Psychological Association (2016) Forensic Psychology, Washington DC, USA.

7. Dietz P (1998) Mass, serial, and sensational homicides. Bull N Y Acad Med 62(5): 477-491.

8. Drukteinis AM (1992) Serial murder-the heart of darkness. Psychiatric Annals 22(10): 532-538.

9. Ferreira C (2000) Serial killers-victims of compulsion or masters of control? in The Science, Treatment, and Prevention of Antisocial Behaviors. In: Fishbein DH (2000) Serial Killers Civic Research Institute, Inc, Kingston New Jersey, USA, pp. 15-17.

10. Seager Stephen (2014) Behind the Gates of Gomorrah: A Year with the Criminally Insane Hardcover.

11. Schlesinger LB (1998) Pathological narcissism and serial homicide: review and case study. Current Psychology 17(2): 212-221.

12. Scholte EM (1999) Factors predicting continued violence into young adulthood. J Adol 22(1): 3-20.

13. Stote R, Standing L (1995) Serial and multiple homicide: is there an epidemic? Social Behavior and Personality 23(4): 313-318.

14. Walters GD (2000) Disposed to aggression: In search of the violenceprone personality. Aggression and Violent Behavior 5: 177-190.

15. Newton M (2016) An Encyclopedia of Modern Serial Killers.

16. Palermo GB, Knudten RD (1994) The insanity plea in the case of a serial killer. International Journal of Offender Therapy and Comparative Criminology 38(1): 3-16.

17. Keaton MA (2008) Personality Disorder Conceptualization in a Serial Murderer: A Methodological Critique and Proposal. American Journal of Forensic Psychiatry 29(1): 31-48.

18. American Psychiatric Association (2015) Diagnostic and Statistical Manual of Mental Disorders. ( $5^{\text {th }}$ edn), Washington DC, USA.

19. Bureau of Labor Statistics (2010) US Department of Labor Occupational Outlook Handbook.

20. Cattell JM (1895) Measurements of the accuracy of recollection. Science 6(2): 761-766.

21. Claus C, Lidberg L (1999) Serial murder as a "Schahriar syndrome." Journal of Forensic Psychiatry, 10(2): 427-435.

22. Cleckley HM (1988) The Mask of Sanity. ( $5^{\text {th }}$ edn), CV Mosby Company, New York, USA, pp. 88-96.

23. Frye v. United States (1923) Washington DC, USA.

24. Groth Marnat G (1999) Handbook of Psychological Assessment. (3 $3^{\text {rd }}$ edn), John Wiley and Sons, Inc, New York, USA.

25. Gudjonsson GH (2012) False confessions and correcting injustices. New England Law Review 46: 689-709.

26. Joint Commission on Accreditation of Health Organizations (2016) The JCAHO, Washington DC, USA.

27. Lamiell JT (2010) Introducing William Stern (1871-1938) Hist Psychol 15(4): 379-384.

28. Marston, W (1917) "Systolic blood pressure symptoms of deception." Journal of Experimental Psychology 2(2): 117-163.

29. Miller M (2000) A model for the assessment of violence. Harvard Review Psychiatry 7: 299-304. 
30. Munsterberg H (1909) On the witness stand: Essays on psychology and crime. Doubleday Publishers, New York, USA, p. 24-25.

31. Ray WJ (1998) Methods toward a Science of Behavior and Experience $\left(6^{\text {th }}\right.$ edn), Wadsworth Publications, Belmont, California, USA.

(c)

This work is licensed under Creative Commons Attribution 4.0 License

DOI: 10.19080/JFSCI.2017.03.555614
32. Wilson C, Seaman, D (2007) The Serial Killers: A Study in the Psychology of Violence. Virgin Book Publishers, New York, USA, 228-249.

33. Wrightsman L, Fulero S (2005) Forensic Psychology. Wadsworth Publishing Company, Belmont, California, USA.

\section{Your next submission with Juniper Publishers} will reach you the below assets

- Quality Editorial service

- Swift Peer Review

- Reprints availability

- E-prints Service

- Manuscript Podcast for convenient understanding

- Global attainment for your research

- Manuscript accessibility in different formats

( Pdf, E-pub, Full Text, Audio)

- Unceasing customer service

Track the below URL for one-step submission https://juniperpublishers.com/online-submission. 